\title{
O canto coral como ferramenta de educação musical utilizando-se referenciais freirianos
}

\author{
Arlindo Leandro Gomes* \\ Júnia Maria Geraldo** \\ Edgar Pereira Coelho***
}

\section{Resumo}

Este artigo apresenta uma reflexão crítica sobre as perspectivas de se utilizar as influências pedagógicas de Paulo Freire na educação musical, principalmente por meio da prática do canto coral. A escola é um espaço privilegiado para o ensino de música. No entanto, a falta de docentes habilitados em música e a perda da identidade da educação musical como disciplina integrante do currículo faz com que seu ensino seja desprestigiado nas escolas brasileiras. Uma perspectiva de se trabalhar conceitos de música na escola é por meio do canto coral, envolvendo habilidades de socialização, ritmo e expressão corporal. Os dados apontam que os referenciais freirianos são contemporâneos e aplicáveis à educação musical. É possível tornar a prática de canto coral uma ferramenta para maior igualdade social, consciência ética, política e social dos sujeitos e grupos, principalmente os menos privilegiados. As escolas brasileiras deveriam garantir o acesso à educação musical como um direito para todos.

Palavras-chave: Canto coral. Música. Educação. Escola. Paulo Freire.

* Licenciado em Música pela Universidade Federal de Ouro Preto UFOP-MG. Especialista em Educação Musical e Ensino de Arte pela Universidade Cândido Mendes UCAM-RJ Tenor, solista, regente de coral, professor de música e canto, compositor e arranjador. juniadrive1@gmail.com .

** Doutora pela Universidade Federal de Viçosa. Docente do Instituto Federal de Educação, Ciência e Tecnologia do Sudeste de Minas Gerais.

junia.maria@ifsudestemg.edu.br.

*** https://orcid.org/0000-0002-4392-4356. Universidade Federal de Viçosa. edgar.coelho@ufv.br. 


\section{Choral singing as a musical education tool using freirian references}

\section{Abstract}

This article presents a critical reflection on the perspectives of using Paulo Freire's pedagogical influences in musical education, mainly through the practice of choral singing. The school is a privileged space for teaching music. However, the lack of qualified music teachers and the loss of the identity of music education as an integral part of the curriculum mean that its teaching is discredited in Brazilian schools. One perspective of working on music concepts at school is through choral singing, involving socialization skills, rhythm and body expression. The data show that Freire's references are contemporary and applicable to music education. It is possible to make the practice of choral singing a tool for greater social equality, ethical, political and social awareness of subjects and groups, especially the less privileged. Brazilian schools should guarantee access to music education as a right for all.

Keywords: Choral singing. Music. Education. Teaching. Paulo Freire.

\section{El canto coral como herramienta de educación musical utilizando referencias freirianas}

\section{Resumén}

Este artículo presenta una reflexión crítica sobre las perspectivas del uso de las influencias pedagógicas de Paulo Freire en la educación musical, principalmente a través de la práctica del canto coral. La escuela es un espacio privilegiado para la enseñanza de la música. Sin embargo, la falta de profesores de música calificados y la pérdida de la identidad de la educación musical como parte integral del plan de estudios hacen que su enseñanza esté desacreditada en las escuelas brasileñas. Una perspectiva del trabajo en conceptos musicales en la escuela es a través del canto coral, que involucra habilidades de socialización, ritmo y expresión corporal. Los datos muestran que las referencias de Freire son contemporáneas y aplicables a la educación musical. Es posible hacer de la práctica del canto coral una herramienta para una mayor igualdad social, conciencia ética, política y social de los sujetos y colectivos, especialmente los menos privilegiados. Las escuelas brasileñas deben garantizar el acceso a la educación musical como un derecho de todos

Palabras clave: Canto coral. Música. Educación. Enseñanza. Paulo Freire. 


\section{Introdução}

Do início da década de 1920 até o fim da década de 1960, a Educação Musical era obrigatória nas escolas do Brasil, sendo representada pelo canto orfeônico, método que foi definitivamente extinto após a promulgação da Lei 5.692/1971, na qual a música, artes visuais, teatro e dança passaram a compor uma só disciplina, a "Educação Artística" (posteriormente denominada "Arte" pela Lei 9.394/1996) (VILLA LOBOS, 1937; BRASIL, 1971; BRASIL, 1996). Desde então nota-se nitidamente um grande enfraquecimento da área de Educação Musical, que se alastra até os dias atuais.

A Lei federal $n^{\circ} 11.769 / 2008$, que estabelece a obrigatoriedade do ensino de música nas escolas de educação básica, foi uma tentativa de retomar o processo de valorização da música (BRASIL, 2008). No entanto, a Lei no 13.278/16 extinguiu o ensino de música obrigatório. Assim, a falta de docentes habilitados em música e perda da identidade da Educação Musical como disciplina integrante do currículo faz com que seu ensino ainda seja desprestigiado. A maioria dos professores leigos em música a utilizam apenas de forma lúdica, visando complementar a sua didática em sala de aula. Poucos licenciados em música ou professores com conhecimento na área atuam no ensino de artes nas escolas de ensino fundamental, o que contribui para distorção no ensino de música. Soma-se a isto a dificuldade enfrentada pelos licenciados em música para motivar os educandos e tornar o ensino de música atrativo, pois foi criada uma imagem de que a música é apenas uma atividade lúdica e muitas vezes considerada pelos discentes como conteúdo "menos importante” (LOUREIRO, 2003; LEMOS JÚNIOR, 2012).

A busca de um novo espaço na escola é constante, visando com ambição um dia transformar a Educação Musical efetivamente em uma disciplina. Evidentemente que essa inserção sofre os mesmos problemas ora provados em outras áreas, mas essa dificuldade é aumentada uma vez que não existe um sistema para um ensino musical nas escolas do ensino fundamental e um desconhecimento enorme sobre a importância da Educação Musical no currículo escolar (LEMOS JÚNIOR, 2012). 
Segundo Fucci Amato (2009), o canto coral pode se tornar uma ferramenta para o ensino prático-teórico de música e para inclusão sociocultural. Entretanto, é necessário adaptá-lo à realidade dos educandos, pois muitas vezes o coro é empregado na forma tradicional, baseado no estilo de música europeu, sem considerar o conhecimento musical prévio e a vivência de seus coralistas. Ainda, é necessário popularizar o canto coral principalmente para os estudantes de escolas de comunidades carentes que muitas vezes não têm oportunidade de participar ou conhecimento a respeito desta modalidade musical (FUCCI AMATO, 2007; 2009). Nesta perspectiva, o uso de referenciais freirianos na educação musical pode contribuir como elemento gerador de conhecimento e transformação individual e social, refletindo sobre a valorização do conhecimento do estudante, seu cotidiano, seu contexto social, sua criatividade. É possível que uma adaptação do círculo de cultura, formulado por Paulo Freire, como metodologia de intervenção de investigação científica possa ser útil nesta empreitada (ROMÃO et al., 2006; FREIRE, 2014; LOPES , 2015).

Diante do exposto, o objetivo deste trabalho é contribuir com reflexões sobre a inserção do ensino de música nas escolas públicas brasileiras, filiando-se às bases teóricas de Paulo Freire (FREIRE, 2002; 2008; 2014) e do canto coral (FERNANDES; KAYAMA; ÖSTERGREN, 2001; FUCCI AMATO, 2007; 2009), visando compreender e promover meios para que práticas de educação musical sejam capazes de tornar os sujeitos-pesquisandos competentes dos recursos da música e (re)leitores do seu conhecimento.

\section{Breve histórico sobre o ensino de música no brasil}

O ensino de música no Brasil remete ao descobrimento do país, sendo utilizado pelos jesuítas durante o processo de colonização, como forma de escolarização dos indígenas de acordo com a visão católica e nos colégios da elite portuguesa (LOUREIRO, 2003). Em 1854, o ensino de música foi inserido oficialmente nas escolas públicas do Brasil. Em 1890, a legislação brasileira passou 
a exigir formação específica para o professor de música (LEMOS JUNIOR, 2012). No entanto, apenas na década de1920 houve expansão do ensino de música no país, influenciada pelo movimento da Escola Nova liderado pelos pedagogos Fernando de Azevedo e Anísio Teixeira, além do músico e maestro Heitor Villa Lobos. Desta forma, o ensino básico passa a comtemplar a disciplina "Canto Orfeônico” em seu currículo. Com origem europeia o canto orfeônico objetivava democratizar o acesso à música e ao seu ensino em todas as camadas sociais, utilizando canto coletivo acompanhado ou não por instrumentos e sem exigência de conhecimento musical ou treinamento vocal prévio (LEMOS JUNIOR, 2012).

\begin{abstract}
A música era elemento imprescindível à educação, pois reunia todos os elementos essenciais para a formação musical, pois o canto coletivo apresentava grande poder de socialização e integração da comunidade e, o mais importante, pelo seu aspecto educativo na formação moral e cívica da infância brasileira (VILLA LOBOS, 1937, p. 35).
\end{abstract}

Com o fim do Estado Novo, o ensino de música nas escolas foi se reduzindo, culminando com a sua eliminação do currículo do ensino básico depois da promulgação da Lei 5.692/1971 para integrar parte da disciplina "Educação Artística", juntamente com artes visuais, teatro e dança. Os Parâmetros Curriculares Nacionais consideram o ensino das artes coletivas, incluindo-as na disciplina "Arte" de acordo com a Lei de Diretrizes e Bases da Educação Nacional (LDB) no. 9.394/1996. Entretanto, os profissionais da área de artes e as universidades, mediante a criação de cursos de licenciaturas específicos - como Licenciatura Plena em Música -, questionam a validade da polivalência da disciplina, mostrando a necessidade do aprofundamento em determinada área.

A Lei 11.769, de 19 de agosto de 2008, alterou a Lei 9.394/1996, instituindo a obrigatoriedade do ensino de música nas escolas brasileiras. Com esta Lei, a música passou a ser um conteúdo obrigatório, mas não exclusivo do componente curricular Arte (BRASIL, 2008). Contudo, o cenário educacional brasileiro não se 
preparou para aplicação de tal legislação, em virtude da carência de materiais e espaços adequados para o ensino de música e, principalmente, pela falta de profissionais qualificados para atuar na educação básica (LEMOS JUNIOR, 2012).

Em 2016, a Lei no 13.278/16 alterou o texto da LDB em relação ao ensino da Artes na educação básica e estabeleceu que as artes visuais, a dança, a música e o teatro são linguagens que constituirão o componente curricular, substituindo o texto da Lei $\mathrm{n}^{\mathrm{o}} 11.769 / 08$ que indicava o ensino de música obrigatório. Assim, a última legislação vigente representa um retrocesso para o ensino de música nas escolas brasileiras no que tange a Educação Musical.

\section{Educação musical e canto coral nas escolas brasi- leiras: desafios e perspectivas}

A escola é um espaço privilegiado para o ensino de música, promovendo aos educandos a desinibição, integração social, desenvolvimento vocal, criação de novas práticas culturais, melhora a disposição para o estudo, maior concentração e a capacidade de memorização. Além da função cultural e recreativa, o ensino de música possibilita a apuração do sentido auditivo, da percepção, da memória, do senso rítmico, do órgão fonador e articuladores, dos órgãos ressonadores, dos pulmões, aumenta a capacidade respiratória e circulação do oxigênio no corpo (FERNANDES; KAYAMA; ÖSTERGREN, 2001; SOUSA; LOURENÇO, 2017).

A perda da identidade da música como disciplina, ocorrida em 1971, fez com que o ensino de música nas escolas brasileiras fosse negligenciado. Nas escolas, principalmente na educação infantil e anos iniciais do ensino fundamental, é comum a utilização da música na forma de cantigas, cirandas de rodas, momentos de lazer e festividades, preenchendo meramente função lúdica e de recreação. Na maioria das escolas, a educação tradicional tecnicista é destaque e, com poucas exceções, a música não tem sido utilizada para alfabetização ou para educação musical, especialmente entre as comunidades mais carentes (FERNANDES; KAYAMA; ÖSTERGREN, 2001). 
Corroborando com esta perspectiva, Souza e Lourenço (2017) destacam que a música nas escolas públicas brasileiras tem sido historicamente negligenciada, sendo um privilégio apenas para as classes mais abastardas. Os autores destacam a importância da sociedade como um todo e principalmente das esferas governamentais valorizarem o ensino de música com qualidade na educação básica como uma ferramenta de aprendizagem e de formação cultural ativa e consciente dos educandos, principalmente para os mais necessitados.

Em uma revisão acerca da prática do canto na educação básica, Mateiro, Vechi e Egg (2014) evidenciaram que o canto coral tem sido utilizado nas escolas como atividade curricular e extracurricular, visando a aprendizagem musical - noções de ritmo, melodia e dinâmicas-, a socialização e o desenvolvimento de habilidades específicas para as práticas musicais como afinação, elementos técnicos, percepção e práticas corporais. No entanto, de acordo com esta mesma revisão, os estudos não aprofundaram nas questões relacionadas à técnica vocal e demais habilidades musicais, evidenciando que o ensino do canto coral não tem sido relacionado ao desenvolvimento da técnica e dos aspectos relativos à música em si, estando mais relacionado a atividades lúdicas, jogos e brincadeiras (MATEIRO; VECH; EGG, 2014).

A música e o canto coral na escola devem ser abordados de forma holística e que incentive o pensamento crítico, reflexivo e criativo dos alunos, reduzindo ao máximo a influência midiática no seu ensino. Assim, na escola devem ser abordados vários estilos musicais, e não um único, considerando a realidade trazida pelos alunos - conhecimentos prévios - e dando oportunidade para conhecerem outros estilos, espaços e tempos da música. Além do repertório, poderiam ser ensinados na escola vários outros aspectos da música por meio do canto coral, como ritmo, iniciação à notação musical, elementos da música, técnica vocal, composição e improvisação musical, diferenciação de timbres, duração de tempo, altura dos sons, bem como as relações que os alunos estabelecem 
com o outro e consigo mesmos por meio da música, socialização e autoestima (HUMMES, 2004; REIS; DUARTE, 2018; CASTRO; TEIXEIRA, 2020; CUNHA; FIGUEIREDO, 2020).

A música deveria ser ensinada por um professor habilitado, permitindo que o aluno amplie sua diversidade cultural, faça reflexões e respeite a si mesmo e o outro. Como a música é inerente à vida, todo indivíduo tem direito a aprender música. $\mathrm{O}$ aluno incentivado a criar em música explora melhor sua extensão vocal e sua expressão, amplia seu vocabulário intelectual, incentiva a autonomia e a criatividade, além de contribuir no processo ensino-aprendizagem. Muito mais que a capacidade de cantar, as aulas de música na escola devem proporcionar uma experiência única e significativa para os alunos. Tais aulas devem permitir que os alunos desenvolvam uma postura proativa, com respeito à diversidade cultural e corporal. A simples reprodução com forte influência midiática deve dar espaço ao conhecimento de diversos estilos, de forma livre, dialogada e criativa (REIS; DUARTE, 2018). Neste contexto, é importante que todos os alunos da educação básica tenham acesso à vivência da Música como um todo, como área do conhecimento. Nas aulas devem ser incluídas discussões contemporâneas atuais, que respeitem os conhecimentos prévios e a diversidade cultural dos alunos, além de incentivar a autonomia dos mesmos. Para isto, é importante a presença de um docente habilitado e que invista em uma formação continuada, que tenha uma visão integrada pautada na valorização da diversidade e da experiência coletiva, criativa e plural (REIS; DUARTE, 2018).

\section{Ensino de música nas escolas: interseção do canto coral com os referenciais freirianos}

As concepções de Paulo Freire trazem uma nova visão da educação e do processo ensino-aprendizagem, exigindo do educador uma nova postura, uma maior interação com os problemas da sociedade e percepção da realidade dos educandos, ao contrário da educação "bancária" tradicional. Segundo ele: 
Não é de estranhar, pois, que nesta visão "bancária" da educação os homens sejam vistos como seres de adaptação, do ajustamento quando mais se exercitam os educandos no arquivamento dos depósitos que lhes são feitos, tanto menos desenvolverão em si a consciência crítica que resultaria a sua inserção no mundo como transformadores dele! Como sujeitos (FREIRE, 2014, p. 60).

Freire destaca a importância de um estudo filosófico-antropológico para refletir sobre o próprio homem antes de refletir sobre a educação. O homem deve ser o sujeito de sua própria educação. Não pode ser objeto dela. Por isso, ninguém educa ninguém. A sua busca é permanente. O professor deve ter postura problematizadora, buscando soluções para os desafios do cotidiano, vinculando os conhecimentos, as limitações e a realidade dos estudantes.

\begin{abstract}
Não é possível respeito aos educandos, à sua dignidade, a seu ser formando-se, à sua identidade, fazendo-se, se não se levam em consideração as condições em que eles vêm existindo, se não se reconhece a importância dos "conhecimentos de experiência feitos" com que chegam à escola. O respeito devido à dignidade do educando não me permite subestimar, pior ainda, zombar do saber que ele traz consigo para a escola (FREIRE, 2002, p.71).
\end{abstract}

Desta mesma forma, o conteúdo programático deve condizer com a vivência dos estudantes, transformando os "conteúdos que são retalhados da realidade desconectados da totalidade em que se engedram e em cuja visão ganhariam significação” (FREIRE, 2014, p. 33). Certamente a música está presente em muitas situações ao longo da nossa vida. Cada pessoa, em sua individualidade, tem alguma(s) música(s) repleta(s) de significação, que remete a momentos especiais ou que apenas traz sensação de bem-estar. A música tem como função básica a transmissão de mensagem com ênfase a elementos subjetivos e intersubjetivos, despertando sentimentos e emoções segundo a visão subjetiva dos indivíduos (HUMMES, 2004; REIS; DUARTE, 2018).

O coro pode ser encarado como uma ferramenta eficaz do ponto de vista educacional, pois além de trabalhar a inclusão social, 
a escolha correta do repertório para cada grupo pode aproximar a realidade vivenciada pelos coralistas e permitir a aplicação das concepções de Freire. Para isto, o regente deve se habilitar para promover uma efetiva educação musical.

O regente de um coral deve atuar com a perspectiva de realizar um trabalho de educação musical dos integrantes de seu grupo. Para a condução de um trabalho artístico que envolve um grupo diversificado como um coral, faz-se necessária a capacidade de estabelecer critérios, motivar cada um de seus integrantes, liderá-los e levá-los a uma meta estabelecida. A partir desse processo, pode-se gerar e difundir conhecimentos musicais e vocais, estimulando o aumento da qualidade de vida dentro de uma comunidade e apropriocepção - percepção de si próprio em suas nuances internas (FUCCI AMATO, 2009, p.97).

Embora exija um profissional habilitado, a implantação do canto coral pode ser encarada como uma alternativa de baixo custo, pois necessita basicamente do professor de música e do grupo de coralistas. Diante do exposto, é válido desenvolver um projeto para investigar se a associação entre as concepções de Paulo Freire e o canto coral são um ponto de partida para reforçar a educação musical no ensino básico brasileiro.

O Círculo de Cultura, proposto por Paulo Freire na década de 1960, é um instrumento de expressão e aprendizagem com ênfase na formação de grupos focais no qual os participantes dialogam, lêem, escrevem, discutem e constroem o mundo em que vivem. Este método educativo é fundamentado na proposta pedagógica libertadora e problematizadora de Freire. Romão e colaboradores (2006) propuseram a denominação de "círculo epistemológico" para a metodologia derivada do círculo de cultura, pela consideração dos "pesquisados" como sujeitos da pesquisa. Assim, no círculo epistemológico, pesquisador e pesquisando são sujeitos da pesquisa. O sujeito-pesquisador atua como pesquisador cultural prévio da realidade (visando identificar os temas/ hipóteses geradoras), como animador cultural que provoca e explora as hipóteses geradoras, e como incentivador de discussões mais aprofundadas. Por meio 
do diálogo, o círculo epistemológico transforma sujeitos individuais em sujeitos transindividuais, que superam a soma dos primeiros por meio da construção coletiva do conhecimento (ROMÃO et al., 2006). De acordo com estes autores:

O círculo de cultura reúne pressupostos filosóficos, teóricos e metodológicos para ser adotado não apenas como um método de alfabetização de adultos, mas acima de tudo como um método que mobiliza os participantes do grupo a pensar sobre sua realidade dentro de uma concepção de reflexão-ação. $\mathrm{Na}$ pesquisa, ele pode ser considerado como método estratégico de desenvolvimento da pesquisa participante, na vertente da pesquisa qualitativa de intervenção. Nele, o sujeito-pesquisador se interessa pela leitura que o sujeito-pesquisador tem de seu mundo e, junto com ele, busca desvelar a realidade que está sendo investigada e revelar o conhecimento que dela deriva. (ROMÃO et al., 2006, p. 188).

Diante do exposto, a associação do canto coral com o Círculo de Cultura pode ser uma alternativa no ensino de música. Embora a maioria das obras de Freire abordem a Educação de Jovens e Adultos (EJA), seus referenciais podem ser aplicados a educação de crianças e adolescentes (COELHO; DE MARI, 2013). A prática do canto coral baseando-se nos referenciais freirianos possibilitariam aos educandos (coralistas) a construção da sua própria história, a reflexão sobre os tipos de música que chegam às massas, reflexões sobre exclusão social, novas oportunidades de construção dos conhecimentos musicais e culturais, superação de limites culturais e coletivos (COELHO; DE MARI, 2013).

Fazendo uma analogia com a alfabetização, tão abordada nas obras de Freire, o ensino da música por meio do canto coral e da educação freiriana seria um importante instrumento de alfabetização musical por meio da troca de saberes e rico compartilhamento de experiências culturais, um processo no qual educador e educando são capazes de ensinar e aprender (COELHO; DE MARI, 2013).

Surge a partir desta proposta uma educação problematizadora e viabilizadora de autonomias onde os próprios indivíduos constroem uma passagem do não saber ao saber. Saem da ingenuidade para a consciência 
crítica, tornando-se sujeitos autônomos, construtores de suas realidades e caminhos (COELHO; LOURES, 2012, p.65).

Em sua experiência com o canto coral com crianças das comunidades do Cantagalo e Pavão-Pavãozinho, periferia do Rio de Janeiro-RJ, Lima (2007) utilizou os círculos, debatendo as letras das músicas do repertório do coral como temas geradores (situações problemas) para abordar temas como relações sociais, violência $\mathrm{x}$ paz, relações interpessoais e possibilidades de transformação pelas ações individuais ou coletivas. Segundo a autora, o canto coral mostrou ser uma eficaz prática educativa, incentivando o pensamento crítico-reflexivo e a capacidade de mudança.

\section{Considerações finais}

Diante das reflexões realizadas, ressalta-se a importância da música na formação dos estudantes na educação básica, principalmente aqueles mais carentes. A música, como forma de arte, propicia o desenvolvimento do ser humano e deveria estar disponível para todos da sociedade, e não apenas para as classes dominantes, como tem ocorrido ao longo dos tempos. Assim, é imprescindível e urgente o investimento em educação musical de qualidade nos espaços formais de educação por meio das esferas governamentais.

O canto coral pode ser utilizado como um instrumento de ensino de música no ambiente escolar e, com influência da educação freiriana, poderia abordar questões além das habilidades musicais, como as desigualdades sociais, política e participação na comunidade, inclusão social, interrelações pessoais e com o coletivo, socialização, ética, autoestima, conhecimento e respeito a outras culturas, considerando o cotidiano dos educandos.

Com este artigo, nota-se que a influência pedagógica de Paulo Freire é contemporânea e aplicável na educação musical contribuindo para a libertação dos sujeitos e grupos menos privilegiados. A construção ativa do conhecimento envolve não apenas o educador, mas os estudantes, suas famílias, escolas e demais atores envolvidos no contexto educacional e sociedade. Apesar de desafiador, 
é de suma importância garantir o acesso à educação musical como um direito para todos.

\section{Referências}

BRASIL. Lei $\mathbf{n}^{\mathbf{0}} \mathbf{1 3 . 2 7 8}$, de 2 de maio de 2016. Altera o $\int 6^{\circ}$ do art. 26 da Lei $\mathrm{n}^{\circ}$ 9.394, de 20 de dezembro de 1996, que fixa as diretrizes e bases da educação nacional, referente ao ensino da arte. Brasília, DF: Secretaria-Geral, 2016a. Disponível em: http://www.planalto.gov.br/ccivil_03/_ato2015-2018/2016/lei/113278.htm. Acesso em: 10 set 2021.

BRASIL. Lei $\mathbf{n}^{\mathbf{0}} \mathbf{5 . 6 9 2 / 1 9 7 1}$, de 11 de agosto de 1971. Fixa Diretrizes e Bases para o ensino de $1^{\circ}$ e $2^{\circ}$ graus, e dá outras providências. Diário Oficial, Brasília, DF. Disponível em: http://www.planalto.gov.br/ccivil_03/leis/15692.htm. Acesso em: 10 set 2021 .

BRASIL. Lei $\mathbf{n}^{\mathbf{0}} \mathbf{9 . 3 9 4}$, de 20 de dezembro de 1996. Estabelece as diretrizes e bases da educação nacional. Brasília, DF: Casa Civil, 1996. Disponível em: http:// www.planalto.gov.br/ccivil_03/Leis/L9394.htm. Acesso em: 10 set 2021.

BRASIL. Lei Ordinária no . 11.769, de 18 de agosto de 2008. Altera a Lei no 9.394, de 20/12/1996, Lei de Diretrizes e Bases da Educação, para dispor sobre a obrigatoriedade do ensino da música na educação básica. Diário Oficial, Brasília, DF. Disponível em: http://www.planalto.gov.br/ccivil_03/_ato2007-2010/2008/lei/ 111769.htm. Acesso em: 10 set 2021.

CASTRO, Ronaldo Eismann de; TEIXEIRA, Maria do Rocio Fontour. Music in education: a possibility to be expanded in the national scenario. Research, Society and Development, v. 9, n. 7, p. e604974082, 2020.

COELHO, Edgar Pereira; DE MARI, Cezar Luiz. Paulo Freire e a Educação de Jovens e Adultos: uma abordagem interdisciplinar. Revista Educação Online PUC-Rio, n. 14, p.39-53, 2013.

COELHO, Edgar Pereira; SANTOS, Marcelo Loures dos. Escola, subjetividade e opressão: a análise de um estudo de caso a partir de González Rey e Paulo Freire. In: COELHO, Edgar Pereira; SANTOS, Geraldo Márcio Alves dos; DE MARI, Cezar Luiz (Orgs). Educação e formação humana: múltiplos olhares sobre a práxis educativa. CRV: Curitiba, 2012, p. 54-72.

CUNHA, Conceição de Maria; FIGUEIREDO, Sérgio Luiz Ferreira de. Música nas disciplinas de Didática de um Curso de Magistério em nível médio: aprendizagens colaborativas. Revista entreideias, v. 9, n. 2, p.43-62, 2020. 
FERNANDES, Angelo José; KAYAMA, Adriana Giarola; ÖSTERGREN, Eduardo Augusto. A prática coral na atualidade: sonoridade, interpretação e técnica vocal. Revista Música Hoje. v. 6, n. 1, p. 55-62, 2001.

FREIRE, Paulo. Educação como Prática da Liberdade. $31^{a}$ ed. São Paulo: Ed. Paz e Terra SA, 2008.

FREIRE, Paulo. Pedagogia da autonomia. 22 ed. São Paulo: Paz e Terra, 2002.

FREIRE, Paulo. Pedagogia do oprimido. 56 ed. Rio de Janeiro: Paz e Terra, 2014.

FUCCI AMATO, Rita de Cássia. Música e políticas socioculturais: a contribuição do canto coral para a inclusão social. Opus, Goiânia, v. 15, n. 1, p. 91-109, jun. 2009.

FUCCI AMATO, Rita de Cássia. O canto coral como prática sócio-cultural e educativo-musica. Opus, Goiânia, v. 13, n. 1, p. 75-96, jun. 2007.

HUMMES, Júlia Maria; Por que é importante o ensino de música? Considerações sobre as funções da música na sociedade e na escola. Revista da ABEM, v. 12, n. 11, 17-25, set. 2004 .

LEMOS JÚNIOR, Wilson. História da educação musical e a experiência do canto orfeônico no Brasil. EccoS, São Paulo, n. 27, p. 67-80. jan./abr. 2012.

LIMA, Maria José Chevitarese de Souza. O Canto Coral como Agente de Transformação Sóciocultural nas comunidades do Cantagalo e Pavão-Pavãozinho: Educação para Liberdade e Autonomia. 2007. 270 f. Tese (Doutorado em Psicossociologia de Comunidade e Ecologia Social) - Instituto de Psicologia, Universidade Federal do Rio de Janeiro, Rio de Janeiro, 2007. Disponível em: http://pos.eicos.psicologia.ufrj.br/wp-content/uploads/mjchevitarese.pdf Acesso em: 10 set 2021 .

LOPES, Raphael Gregory Bazílio; KERR, Tiemi Okimura. O ensino das lutas na Educação Física escolar: uma experiência no ensino fundamental. Motrivivência, v. 27, n. 45 , p. $262-279$, set. 2015.

LOUREIRO, Alícia Maria Almeida. O ensino de música na escola fundamental. Campinas: Papirus, 2003.

MATEIRO, Teresa; VECHI, Hortênsia; EGG, Marisleusa de Souza. A prática do canto na escola básica: o que revelam as publicações da ABEM (1992-2012). Revista da ABEM, v. 22, n. 33, p. 57-76, 2014. 
REIS, João Gome; DUARTE, Pedro. O currículo, a educação musical e as realidades individuais de cada estudante: um ensaio em defesa da inclusão cultural no ensino de música. Revista da ABEM, v. 26, n. 41, p. 5-20, 2018.

ROMÃO, José Eustáquio; CARRÃO, Eduardo Vitor Miranda; CABRAL, Ivone Evangelista; COELHO, Edgar Pereira. Círculo epistemológico: círculo de cultura como metodologia de investigação. Educação \& Linguagem, v. 13, p. 173-195, 2006.

SOUSA, Paulo Cezar Pardim de; LOURENÇO, Renata. Um breve histórico das legislações sobre o ensino de música no Brasil. An. Sciencult, v.7, n.1, p. 358370, 2017.

VILLA LOBOS, Heitor. O ensino popular de música no Brasil: o ensino da música e do canto orfeônico nas escolas. Rio de Janeiro: Secretaria Geral de Educação e Cultura, 1937. 